$\mathrm{HbA}_{1}$ was above the upper limit of normal only in patients who had repeated fasting blood glucose values exceeding $7 \mathrm{mmol} / \mathrm{l}$.

Lastly, only 37 of the 106 patients studied had fasting blood glucose values below $7 \mathrm{mmol} / 1$; some were up to $16 \mathrm{mmol} / 1$ $(288 \mathrm{mg} / 100 \mathrm{ml})$.

We thank Dr D R Coles for allowing us to study patients under his care; Mr D White and Mrs G Barron for technical work; Drs A Hughes and C Roberts for statistical advice; and Miss Anne Brown and Mrs Zina Fear for typing the manuscript.

\section{References}

1 Jarrett RJ, Keen H. Hyperglycaemia and diabetes mellitus. Lancet 1976 ;ii:1009.

2 Wakelin K, Goldie DJ, Hartog M, Robinson AP. Measurement of capillary blood glucose in filter paper spots : an aid to the assessment of diabetic control. $\mathrm{Br}$ Med $\mathcal{F} 1978$;ii :468-9.
${ }^{3}$ West P, Marsland IG, Bradshaw P. Automated capillary blood spot glucose estimation. Med Lab Sci 1979;36:379-80.

4 Welch SG, Boucher BJ. A rapid micro-scale method for the measurement of haemoglobin Al $(a+b+c)$. Diabetologia 1978;14:209-11.

${ }^{5}$ Holman RR, Turner RC. The quest for basal normoglycaemia. Lancet $1977 ; \mathrm{i}: 469$.

${ }^{6}$ Dorf A, Ballentine EJ, Bennett PH. Retinopathy in Pima Indians. Relationships to glucose level, duration of diabetes, age at diagnosis of diabetes, and age at examination in a population with a high prevalence of diabetes mellitus. Diabetes 1976;25:554-60.

${ }^{7}$ Keen H, Jarrett RJ, Chlouverakis C, et al. The effect of treatment of moderate hyperglycaemia on the incidence of arterial disease. Postgrad Med F 1968;44:960-5.

${ }^{8}$ Reid DP, Hamilton PJS, Keen H, Brett GZ, Jarrett RJ, Rose G. Cardiorespiratory disease and diabetes among middle-aged male civil servants. Lancet $1974 ; \mathrm{i}: 469$.

${ }^{9}$ Graf RJ, Halter JB, Porte D. Glycosylated haemoglobin in normal subjects and subjects with maturity onset diabetes: evidence for a saturable system in man. Diabetes $1978 ; 27: 834-9$.

(Accepted 28 November 1979)

\section{Summary and conclusions}

One hundred and sixty ex-servicemen who had been prisoners of war in south-east Asia during 1942-5 were investigated for infection with Strongyloides stercoralis. Larvae were found in $44(27.5 \%)$ of the men, who had therefore been infected for 34-37 years. Direct microscopy of the faeces was the most successful diagnostic method, giving a positive result in 37 cases (84\%); multiple examinations were often necessary. Faecal culture was positive in 30 cases (68\%), but examination of duodenal fluid obtained with the string test gave a positive result in only $17(39 \%)$. The mean blood eosinophil count and mean serum IgE concentration were higher in the infected men, though normal values were often found in individual cases. Clinical manifestations of isolated strongyloides infection were analysed by comparing the infected men with control groups of ex-prisoners in south-east Asia without proved strongyloidiasis and exprisoners in Europe. Twenty-nine infected men (66\%) complained of non-specific urticaria, and $13(30 \%)$ had pathognomonic larva currens. Gastrointestinal symptoms significantly more common in the infected group were diarrhoea, indigestion, lower abdominal pain, pruritus ani, and weight loss $(p<0.05-p<0.0005)$.

The study group was thought to be reasonably representative of Allied ex-servicemen imprisoned in southeast Asia during the second world war. Probably there are many thousands of infected persons in several countries. The worm has an unusual ability to multiply, and larvae may spread throughout the body in immunosuppressed subjects.

Department of Medicine, University of Western Australia, and the Repatriation General Hospital, Nedlands, Western Australia 6009

D I GROVE, FRACP, DTM\&H, senior lecturer

\section{Introduction}

The nematode Strongyloides stercoralis is widely distributed throughout the tropics and subtropics. Infection is acquired when worms penetrate the skin; they pass via the blood stream to the lungs, ascend the respiratory tract, are swallowed, and grow into adult worms in the mucosa of the small intestine. The organism has an unusual ability to replicate in man; consequently infection may persist for years. The importance of the infection is twofold. Firstly, it may contribute to the ill health of infected persons, although this has been difficult to document because of concurrent infections with other intestinal parasites. Secondly, an overwhelming infection with widespread dissemination of larvae may supervene should such persons become immunosuppressed. ${ }^{1}$

Strongyloidiasis has been reported in Allied ex-servicemen who were prisoners of war in south-east Asia during the second world war. ${ }^{2} 3$ I decided to assess the prevalence of strongyloidiasis in an unselected sample of such men, compare the efficacies of various diagnostic methods, and try to delineate the clinical manifestations of the infection.

\section{Subjects and methods}

Letters were sent to all 201 former members of the $2 / 4$ machine-gun battalion who were identified by their association as living in the Perth metropolitan area; 160 men $(80 \%)$ replied. Their ages ranged from 55 to 80 years, with a median of 62 . The battalion was raised in Perth, captured at the fall of Singapore in January 1942, then dispersed among other Allied prisoners of war. Its members worked on the Burma-Thailand railway in 1943, and were then scattered throughout south-east Asia and Japan.

Each respondent was interviewed. In most cases it was also possible to review the clinical records from the years immediately after the war. Faeces were examined for larvae of $S$ stercoralis by direct microscopy and culture. Faeces ( $1 \mathrm{~g}$ ) were homogenised and diluted in $50 \mathrm{ml}$ water, then $0.5 \mathrm{ml}$ aliquots were placed in Sedgewick-Rafter chambers and 10 chambers examined. Faeces $(2 \mathrm{~g})$ were smeared on moistened filter paper, placed in a slanted Petri dish containing a small volume of water, incubated at room temperature for two 
weeks, and the sediment examined for parasites. Duodenal samples were obtained with a string ${ }^{4}$ (Entero-test capsules, Hedeco, Palo Alto, California) and examined by direct microscopy. Haemoglobin concentrations and total and differential white cell counts were determined. Serum IgG, IgA, IgM, and C3 concentrations were measured with Diffu-gen plates and standards (Oxford Laboratories, Foster City, California). Serum IgE concentrations were measured with the Phadebas PRIST kit (Pharmacia, Uppsala, Sweden).

If worms were not found but the diagnosis was strongly suspected because of a history typical of larva currens or urticaria, a report of larvae in the faeces in the immediate postwar years, or a serum IgE concentration exceeding $250 \mathrm{U} / \mathrm{ml}$ for which no other cause was apparent the string test and faecal examinations were repeated. If the results were again negative patients early in the series were subjected to endoscopy and a duodenal aspirate and biopsy specimens of mucosa obtained. This procedure had a low yield, however, and was replaced by repeated examination of faecal specimens obtained on different days.

To analyse the prevalence of symptoms I included as a further control group ex-servicemen who had been prisoners of war in Europe; there was no reason to suspect that they had been exposed to $S$ stercoralis. A random sample of 43 former members of the $2 / 11$ battalion, which had been captured in Crete, were questioned. Their ages ranged from 55 to 77 years, with a median of 63 .

The data were analysed by $\chi^{2}$ test (with Yates's correction when necessary) and Student's $t$ test, as appropriate. When the $t$ test was used on populations with a log-normal distribution analyses were performed on logarithmically transformed values, but the results are reported here as the geometric mean and range-that is, antilog (logarithmic mean-logarithmic SD) to antilog (logarithmic mean + logarithmic SD).

\section{Results}

A parasitological diagnosis was made in $44(27.5 \%)$ of the men. This was achieved at the first attempt in 30 cases $(68 \%)$. The most successful routine method was direct microscopy of the faeces, examination of duodenal fluid obtained by the string test being of least value (table I). The value of direct microscopy was proportional to the number of faecal specimens obtained and the number of preparations inspected (table II). There was only one patient who had

TABLE I-Efficacy of various diagnostic methods in 44 men with strongyloidiasis. Results expressed as number (percentage) of cases diagnosed

\begin{tabular}{|c|c|c|c|c|c|c|}
\hline No of times used & & & & $\begin{array}{c}\text { Faecal } \\
\text { microscopy }\end{array}$ & $\begin{array}{l}\text { Faecal } \\
\text { culture }\end{array}$ & $\underset{\text { test }}{\text { String }}$ \\
\hline $\begin{array}{ll}\text { Once } & \ldots \\
\text { Twice or more } & \ldots\end{array}$ & $\because$. & $\begin{array}{l}. \\
.\end{array}$ & $\because$ & $\begin{array}{l}29(66) \\
37(84)\end{array}$ & $\begin{array}{l}24(55) \\
30(68)\end{array}$ & $\begin{array}{l}14(32) \\
17(39)\end{array}$ \\
\hline
\end{tabular}

TABLE II-Relation between numbers of slides of faeces examined by microscopy and rate of detection of $S$ stercoralis in 37 infected men. (Ten slides prepared from each specimen)

\begin{tabular}{lcllllllll}
\hline $\begin{array}{l}\text { No of slides examined } \\
\text { No of men positive }\end{array}$ & $1-$ & $6-$ & $11-$ & $16-$ & $21-$ & $26-$ & $31-$ & $36-$ & $>40$ \\
2
\end{tabular}

a positive string test result but in whom larvae were not detected in the faeces. Duodenoscopy with aspiration of duodenal fluid and mucosal biopsy was unsatisfactory. Six patients with proved strongyloidiasis were investigated by duodenoscopy; larvae were seen in the aspirate from one man, and mucosal biopsy was nondiagnostic in all cases. Nine men in whom strongyloidiasis was suspected but never proved underwent endoscopy; no worms were found.

Two men are excluded from the following analyses: larvae were seen in faecal specimens in the early postwar years, but despite prolonged searching and repeated attacks of larva currens in one case they could not be detected in this study.

There were no significant differences between men with strongyloidiasis and uninfected ex-servicemen with respect to haemoglobin concentrations and blood neutrophil, lymphocyte, and monocyte counts. Blood eosinophil counts (fig 1), however, were higher ( $p<$
0.001 ) in men with strongyloidiasis (geometric mean $0.361 \times 10^{9} / 1$; range $\left.0 \cdot 108 \times 10^{9}-1 \cdot 209 \times 10^{9} / 1\right)$ than in ex-prisoners without strongyloidiasis $\left(0.052 \times 10^{9} / 1 ; 0.010 \times 10^{9}-0.501 \times 10^{9} / 1\right)$.

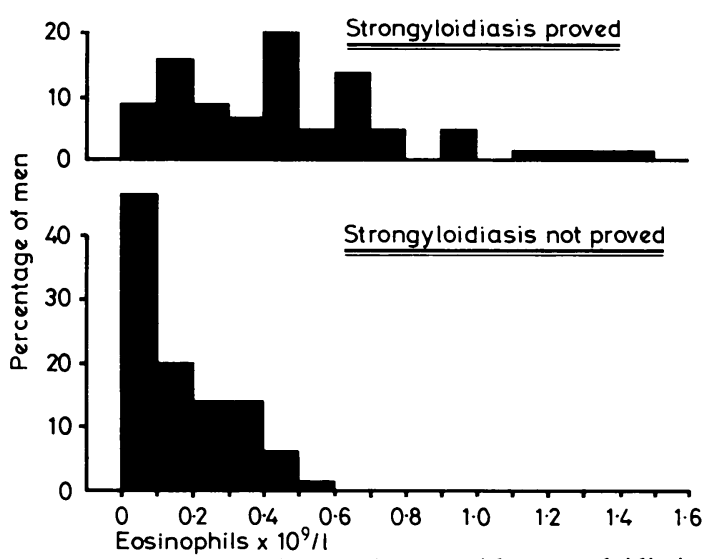

FIG 1-Blood eosinophil counts in men with strongyloidiasis and ex-prisoners in south-east Asia without proved strongyloidiasis.

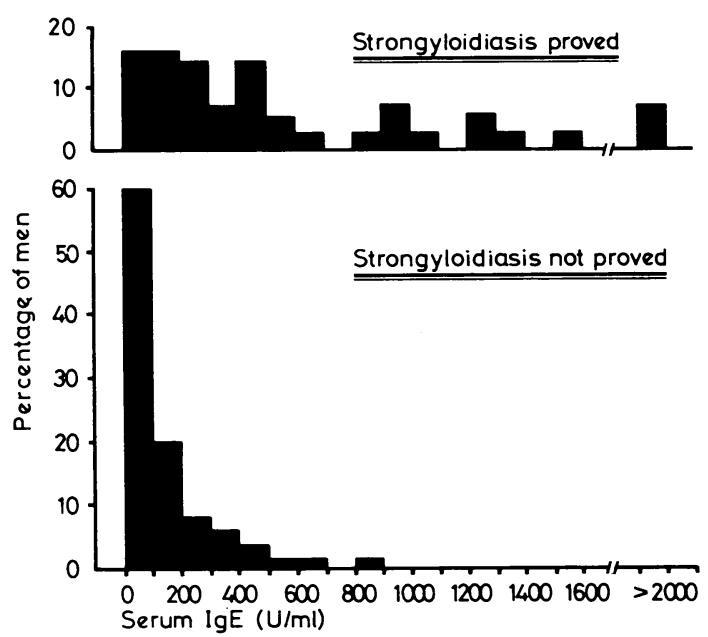

FIG 2-Serum IgE concentrations in men with strongyloidiasis and ex-prisoners in south-east Asia without proved strongyloidiasis.

There were no significant differences in serum IgG, IgA, IgM, and $\mathrm{C} 3$ concentrations: respective values in men with strongyloidiasis were $13.4 \pm$ SD $3 \cdot 7,2 \cdot 81 \pm 1 \cdot 57,2 \cdot 14 \pm 1.28$, and $1.49 \pm 0.28 \mathrm{~g} / 1$ while those in ex-prisoners in south-east Asia without strongyloidiasis were $12.4 \pm \mathrm{SD} 3.6, \quad 3.07 \pm 1.43,1.96 \pm 1.36$, and $1.55 \pm 0.28 \mathrm{~g} / 1$. Serum IgE concentrations (fig 2$)$, however, were higher $(\mathrm{p}<0.001)$ in men with strongyloidiasis (geometric mean $311 \mathrm{U} / \mathrm{ml}$; range $66-1470 \mathrm{U} / \mathrm{ml}$ ) than in men without strongyloidiasis $(64 \mathrm{U} / \mathrm{ml}$; $17-245 \mathrm{U} / \mathrm{ml}$ ).

There were no age differences between infected and uninfected men. Men with strongyloidiasis were significantly thinner than uninfected men $(p<0.05)$ when their height:weight $(\mathrm{cm}: \mathrm{kg})$ ratios were compared; the infected men had a geometric mean ratio of $2 \cdot 41$ (range $2 \cdot 12-2 \cdot 74$ ), whereas that of the uninfected men was $2 \cdot 29(2 \cdot 00-2 \cdot 62)$. This was confirmed $(p<0.05)$ when men with strongyloidiasis were compared with the 43 men who had been prisoners in Europe; this group had a geometric mean ratio of $2 \cdot 27$ $(2 \cdot 00-2 \cdot 59)$

Table III lists the symptoms recorded in the men with strongyloidiasis, in the uninfected ex-prisoners in south-east Asia, and in the ex-prisoners in Europe. Symptoms referable to the skin and gastrointestinal tract were significantly more common in the infected group. Predominant symptoms were larva currens, urticaria, diarrhoea, pruritus ani, indigestion, lower abdominal pain, and 
persistent or recent weight loss $(p<0.05-p<0.0005)$. Urticaria was characterised by crops of stationary weals, particularly on the buttocks and around the waist, lasting one to two days and recurring at irregular intervals. Larva currens was typical, with transient urticarial eruptions migrating in a serpiginous fashion. There was no significant difference in peptic ulceration: nine men with strongyloidiasis $\left(20^{\circ} \%\right)$ and 17 uninfected men $(15 \%)$ gave a history of definite ulceration. Respiratory

TABLE III-Prevalence of symptoms in men with strongyloidiasis, uninfected men who were also ex-prisoners of war in south-east Asia, and ex-servicemen who had been prisoners in Europe. Figures are numbers (percentages) of subjects

\begin{tabular}{|c|c|c|c|c|c|}
\hline & & & \multicolumn{2}{|c|}{ Prisoners in south-east Asia } & \multirow[b]{2}{*}{$\begin{array}{c}\text { Prisoners in } \\
\text { Europe } \\
(n=43)\end{array}$} \\
\hline & & & $\begin{array}{c}\text { Strongyloidiasis } \\
\text { proved } \\
(\mathrm{n}=44)\end{array}$ & $\begin{array}{l}\text { Strongyloidiasis } \\
\text { not proved } \\
(\mathrm{n}=114)\end{array}$ & \\
\hline \multicolumn{2}{|c|}{ Non-specific urticaria } & . & $29(66)$ & $3(3) * * *$ & $0 * *$ \\
\hline Larva currens & .. & . & $13(30)$ & $0 * * *$ & $0^{* * *}$ \\
\hline Diarrhoea & $\because$ & $\because$ & $20(45)$ & $26(23)^{* *}$ & $7(16)^{*}$ \\
\hline Indigestion & $\because$ & $\because$ & $32(73)$ & $52(46)^{* * *}$ & $19(44)^{*}$ \\
\hline Constipation & $\therefore$ & $\because$ & 1 (2) & 19 (17)* & $7(16)$ \\
\hline Pruritus ani & $\because$. & $\therefore$ & $26(59)$ & 49 (43)* & $17(40)$ \\
\hline Weight loss & $\because$ & $\therefore$ & $10(23)$ & 13 (11)* & 2 (5)* \\
\hline Abdominal pain & & .. & $25(57)$ & $47(41)$ & $13(30) *$ \\
\hline Heartburn & .. & $\because$ & $22(50)$ & $38(33)$ & $14(33)$ \\
\hline Reflux & $\because$ & $\because$ & 17 (39) & $44(39)$ & $17(40)$ \\
\hline Anorexia & .. & . & $11(25)$ & 22 (19) & 1 (2) \\
\hline Nausea .. & $\ldots$ & $\ldots$ & $10(23)$ & $23(20)$ & $10(23)$ \\
\hline Vomiting.. & $\because$ & $\therefore$ & 3 (7) & $10(9)$ & $5(12)$ \\
\hline Cough $\quad$. & $\therefore$ & $\because$ & $15(34)$ & 33 (29) & $13(30)$ \\
\hline Dyspnoea & $\because$ & $\because$ & $14(32)$ & $51(45)$ & $22(51)$ \\
\hline Chest pain & $\therefore$ & $\therefore$ & 4 (9) & $18(16)$ & $13(30)$ \\
\hline Nervousness & $\therefore$ & $\because$ & 19 (43) & $62(54)$ & $13(30)$ \\
\hline Lack of energy & $\therefore$ & $\therefore$ & $21(48)$ & $58(51)$ & $20(47)$ \\
\hline
\end{tabular}

Compared with men with proved strongyloidiasis: ${ }^{*} \mathrm{p}<0.05 ;{ }^{* *} \mathrm{p}<0.005$; ${ }_{* * *} \mathrm{p}<0.0005\left(\%^{2}\right.$ test. $)$

symptoms were not more common in the infected group. No patient with strongyloidiasis had ever been treated with systemic corticosteroids, but seven of the uninfected men $(6 \%)$ had received such treatment. These observations were confirmed when men with strongyloidiasis were compared with men who had been prisoners in Europe. There were no significant differences between men who had been prisoners in Europe and those who had been prisoners in south-east Asia in whom strongyloidiasis could not be proved (table III).

\section{Discussion}

The ability of $S$ stercoralis to multiply in man accounts for its persistence in these ex-servicemen for 34-37 years. Forty-four of the men $(27.5 \%)$ were found to be infected. This is probably an underestimate, however, as diagnostic methods are insensitive, and in several cases the diagnosis was suspected clinically but larvae could not be found despite intensive investigation. Eighty per cent of men approached agreed to participate in the study, so it was probably not particularly biased by patients with symptoms.

The sample of veterans investigated appeared to be reasonably representative of all ex-prisoners of war, since members of the battalion were dispersed fairly randomly among Allied troops. The number of people at risk is difficult to estimate. One hundred and thirty thousand servicemen were lost in the Malaya campaign, comprising 15000 Australian, 15000 Malay, 35000 British, and 65000 Indian troops. ${ }^{5}$ Some 61000 servicemen, mainly Australian and British, but including some American and Dutch, worked on the Thailand-Burma railway. Of these, roughly 12000 are thought to have perished. ${ }^{6}$ Many ex-prisoners have since died, but there must be tens of thousands of ex-servicemen in several countries who are alive and may be infected with $S$ stercoralis.

Strongyloidiasis is notoriously difficult to diagnose parasitologically, which may partly explain the long duration of unsuspected infection in these men. Microscopical examination of faeces remains the mainstay of diagnosis. In most cases the parasite load is low, however, and large and repeated quantities of faeces often need to be examined by direct microscopy or after concentration. Faecal culture is useful but takes several weeks to produce a result. Jones? suggested that examination of duodenal aspirate may be a valuable aid to diagnosis. Beal et $a l^{4}$ developed a simple gelatin capsule containing a coiled string that passes into the duodenum. Using this device they recovered larvae from $91 \%$ of patients with known strongyloidiasis. In my series, however, the string test was successful in only 17 cases $\left(39^{\circ} \%\right)$, even after two attempts. Fluid obtained at duodenoscopy was almost useless; it could be collected only over a short time, and the volume was reduced by atropine given before the procedure. The failure to find worms in any of the biopsy specimens of duodenal mucosa illustrates the low intensity of infection with $S$ stercoralis in these men.

Indirect indices of infection were useful in the group as a whole but of no value in individual cases. Although the mean blood eosinophil count and mean serum IgE concentration were greatly increased, values were sometimes normal in infected men.

Perusal of the clinical records from the early postwar years showed that many men had concurrent infections with hookworm, Ascaris lumbricoides, and Trichuris trichiura. Since these helminths cannot multiply, such infections subsided spontaneously. A clinical diagnosis of amoebiasis had also been made in many men at that time. There was no evidence of current amoebic infection; Entamoeba histolytica was never seen in faecal samples, and tests on sera from several patients with diarrhoea showed no amoebic antibodies. Thus these men provided a unique opportunity to study the clinical manifestations of isolated strongyloides infection. Furthermore, in contrast to other studies, not only were these men unselected but two control groups-namely, ex-servicemen who were also prisoners in south-east Asia but in whom the parasite could not be detected, and ex-servicemen who were prisoners in Europe and thus exposed to privation but not to $S$ stercoralis-were available for comparison.

From the life cycle of $S$ stercoralis the clinical manifestations of infection would be expected largely to reflect lesions in skin, lungs, and gastrointestinal tract. Two uncontrolled studies $^{7} 8$ laid particular emphasis on abdominal complaints. For example, Jones 7 found that the most common symptoms, in decreasing order of prevalence from $79 \%$ to $33 \%$, were abdominal pain, nausea, weight loss, vomiting, and diarrhoea. Respiratory symptoms were not prominent in either series. Twenty-two per cent of Jones's patients suffered urticaria, but this was not noted at all by Hinman. ${ }^{8}$ In a series of 100 British ex-Far East prisoners of war, 11 volunteered a history consistent with larva currens. ${ }^{3}$ In a later series of 602 ex-servicemen, Gill and $\mathrm{Bell}^{\circ}$ found $88(15 \%)$ with $S$ stercoralis in their faeces. In that study, which was conducted retrospectively over 11 years, larva currens occurred in $84 \%$ of infected subjects but gastrointestinal symptoms were not prominent. There was no control group, however. Furthermore, the series was biased by actively soliciting patients with characteristic cutaneous lesions.

$\mathrm{My}$ investigation confirms the high prevalence of strongyloidiasis in ex-prisoners of war in south-east Asia and extends the observations of other workers. Though some men with strongyloides infection were asymptomatic, there was little doubt that the worm had caused much ill health in many men for many years. This could be measured objectively from weight loss, and subjectively from symptoms. Cutaneous manifestations were the most striking symptoms, though not necessarily the most disabling. Respiratory symptoms did not occur more often in patients with strongyloidiasis, but gastrointestinal complaints were significantly more common. The multiplicity of complaints in the control groups is not surprising when the age of the population is considered and illustrates the fallacy of drawing conclusions from infected persons only. There were no significant differences between ex-prisoners in Europe and ex-prisoners in south-east Asia in whom strongyloidiasis could not be proved, thus supporting the importance of the observations in ex-prisoners with proved infection. 
In addition to the morbidity from this organism, however, lies the potential for a fatal illness. Overwhelming strongyloidiasis may occur as an opportunistic infection. ${ }^{1}$ This also devolves from the ability of $S$ stercoralis to multiply; when patients become immunosuppressed host defences break down and filariform larvae spread throughout the body. Gramnegative septicaemia, pneumonia, and meningitis often complicate the direct injury produced by migrating larvae. Such patients commonly fail to respond to thiabendazole and antibiotics. In view of the difficulty of diagnosis, ex-prisoners of war in south-east Asia who are about to receive immunosuppressive agents should probably first be treated prophylactically with thiabendazole.

I thank Miss Jane Blair for excellent technical help, Mr G McDonald for measuring the serum immunoglobulin concentrations, and Drs R Leedman and $T$ Walters for the endoscopic examinations. This study was supported by grants from the Australian Department of Veterans' Affairs and the Rockefeller Foundation.

\section{References}

1 Scowden EB, Schaffner W, Stone WJ. Overwhelming strongyloidiasis; an unappreciated opportunistic infection. Medicine (Baltimore) 1978; a 7:527-44.

${ }^{2}$ Chaun $\mathrm{H}$. The treatment of chronic strongyloidiasis with thiabendazole. Trans $R$ Soc Trop Med Hyg 1967;61:812-6.

${ }^{3}$ Gill GV, Bell DR, Reid HA. Strongyloidiasis in ex-Far East prisoners of war. Br Med $\mathcal{F} 1977 ; \mathrm{i}: 1007-8$.

- Beal CB, Viens P, Grant RG. A new technique for sampling duodenal contents: demonstration of upper small bowel pathogens. Am $\mathcal{F}$ Trop Med Hyg 1970;19:349-52.

5 Bergamini D. Fapan's imperial conspiracy. London: Heinemann, 1971.

- Wigmore L. Australia in the war of 1939-1945. Series 1. Army. Vol IV. The Japanese thrust. Canberra: Australia War Memorial, 1957.

${ }^{7}$ Jones CA. Clinical studies in human strongyloidiasis. I. Semeiology. Gastroenterology 1950;16:743-56.

${ }^{8}$ Hinman EH. A study of 85 cases of Strongyloides stercoralis infection with special reference to abdominal pain. Trans $R$ Soc Trop Med Hyg 1937; 30:531-8.

- Gill GV, Bell DR. Strongyloides stercoralis infection in former Far East prisoners of war. $\mathrm{Br}$ Med $\mathcal{F} 1979$;ii :572-4.

(Accepted 10 December 1979)

\title{
Improved hypnotic treatment using chlormethiazole and temazepam
}

\author{
R S BRIGGS, C M CASTLEDEN, C A KRAFT
}

\section{Summary and conclusions}

The effects of a single $384 \mathrm{mg}$ oral dose of chlormethiazole were compared with those of $20 \mathrm{mg}$ of temazepam and placebo in healthy old and young women (mean ages 72.9 and 24.7 years respectively). Both drugs were effective hypnotics and had no detectable pharmacological action the next morning. Even four hours after administration performance of a simple psychomotor test was not impaired and sway (measured by an ataxiameter) was not increased in either age group. Pharmacokinetic studies showed that chlormethiazole was rapidly absorbed, distributed, and eliminated by both groups, so that minimal plasma concentrations existed 11 hours after administration. Temazepam, however, was less quickly absorbed and distributed, especially in the young group, and substantial amounts remained in the plasma 11 hours after administration. No unwanted effects occurred after temazepam, but 17 of the 20 subjects suffered from nasal irritation after taking chlormethiazole.

Thus hangover effects may be avoided in elderly subjects after they have taken hypnotic drugs, and temazepam and chlormethiazole allow sleep to be interrupted safely.

\section{Introduction}

Since many hypnotics are slowly eliminated from the body, high plasma concentrations persist throughout the day after ad-

Leicester General Hospital, Leicester LE5 4PW

R S BRIGGS, MSC, MRCP, senior registrar in geriatric medicine C M CASTLEDEN, MD, MRCP, senior lecturer in geriatric medicine C A KRAFT, BSC, technician, department of medicine ministration. These produce sedation and impairment of performance of the central nervous system (CNS) and are a major drawback to using hypnotics. ${ }^{12}$ A solution would be to prescribe hypnotics that are rapidly eliminated, so that only small and pharmacologically ineffective concentrations exist the next morning. Chlormethiazole and temazepam, two hypnotics with relatively short half lives, ${ }^{34}$ produce no hangover effects in younger subjects at doses of $768 \mathrm{mg}$ and $20 \mathrm{mg}$ respectively. ${ }^{5}$. Data do not exist, however, for elderly subjects, although in general the elderly are more susceptible to adverse effects after taking hypnotics. ${ }^{7-9}$

Evidence is conflicting on whether hypnotics in the elderly increase their tendency to fall. ${ }^{1011}$ Since old people commonly rise once or more every night, the effect of hypnotic treatment on their ability to do so safely warrants investigation.

We designed this study firstly to establish whether hangover effects the next morning could be avoided in the elderly by giving hypnotics with short elimination half lives; secondly, to relate any differences in CNS performance between young and old subjects after these hypnotics to their respective plasma concentrations; and, finally, to determine whether such hypnotics affect CNS performance a few hours after being taken, increase the likelihood of falls, and still retain their hypnotic action.

\section{Subjects and methods}

Ten old and 10 young female volunteers took part in the study. Their average ages were 72.9 years (range 67-77) and 24.7 years (range 21-31) respectively. All lived independently at home and were apparently in good health with no clinical or biochemical evidence of hepatic, renal, cardiovascular, pulmonary, or CNS disease, apart from one old subject who was mildly hypertensive. One subject in each age group smoked. None took regular medication (including the contraceptive pill), and no drugs were taken within seven days of the study. Each subject gave informed consent to the project, which was approved by the local ethical committee. 